\title{
Response of parkinsonian swallowing dysfunction to dopaminergic stimulation
}

\author{
P C Hunter, J Crameri, S Austin, M C Woodward, A J Hughes
}

\section{Department of Aged Care Services \\ P C Hunter \\ M C Woodward \\ A J Hughes}

Department of Speech Pathology

J Crameri

S Austin

Department of Neurology, Austin and Repatriation Medical Centre, Heidelberg, Victoria, Australia A J Hughes

Correspondence to: Dr Andrew J Hughes, Department of Neurology, Austin and Repatriation Medical Centre

(Repatriation Campus), Heidelberg West, Victoria, Australia 3081.

Received 20 December 1996 and in revised form 23 April 1997

Accepted 22 May 1997

\begin{abstract}
Objectives-To determine the degree of dopaminergic response of swallowing dysfunction in Parkinson's disease.

Methods-Fifteen patients with idiopathic Parkinson's disease and symptomatic dysphagia were studied. All had motor fluctuations in response to long term levodopa therapy. On two separate days, after overnight withdrawal of all antiparkinsonian medication, a modified barium swallow using cinefluoroscopy and different food consistencies was performed before and after administration of oral levodopa and subcutaneous apomorphine.

Results-Despite all patients having an unequivocal motor response to both agents, there were few significant responses in any of the quantitative or qualitative criteria of swallowing dysfunction assessed. The oral preparatory phase, generally considered a more voluntary component of swallowing, showed a response, but not with all consistencies. In a subgroup of patients the pharyngeal phase time also improved.

Conclusions-These findings suggest that parkinsonian swallowing dysfunction is not solely related to nigrostriatal dopamine deficiency and may be due to an additional non-dopamine related disturbance of the central pattern generator for swallowing in the pedunculopontine nucleus or related structures in the medulla.
\end{abstract}

(F Neurol Neurosurg Psychiatry 1997;63:579-583)

Keywords: apomorphine; levodopa; Parkinson's disease; swallowing dysfunction

Swallowing dysfunction is common in idiopathic Parkinson's disease, being symptomatic in up to $50 \%$ of patients but seen in more than $90 \%$ using videofluoroscopy. ${ }^{1-3}$ It is usually considered multifactorial with abnormalities documented in all phases of swallowing. ${ }^{2-9}$ In the oral phase poor bolus formation, lingual festination and tremor, and repetitive tongue elevation are characteristic. In the pharyngeal phase the swallow reflex can be delayed; there may be slowing of pharyngeal transit and pooling in the valleculae and pyriform sinuses. Dysfunction of the upper oesophageal sphincter with incomplete relaxation and reduced opening is also common. ${ }^{2-4} 79$ In the oesophageal phase abnormal oesophageal peristalsis and gastro-oesophageal reflux can be seen. ${ }^{1-3}$ These factors increase the risk of laryngeal penetration and aspiration. ${ }^{3-6} \mathrm{~A}$ disruption of the normal sequencing of swallowing may underlie these abnormalities. ${ }^{7}$

It remains unclear just how responsive these disturbances are to pharmacological intervention. Swallowing dysfunction in Parkinson's disease has traditionally been grouped along with speech and postural disturbance as being resistant to levodopa although evidence for this is not strong. ${ }^{41011}$ We have studied the response of parkinsonian swallowing dysfunction to dopaminergic stimulation with levodopa and the directly acting dopamine receptor agonist apomorphine, using both qualitative and quantitative variables obtained from videofluoroscopic assessment.

\section{Patients and methods}

Fifteen patients ( 12 men, three women) fulfilling the United Kingdom brain bank criteria for the diagnosis of Parkinson's disease, ${ }^{12}$ with symptomatic dysphagia, were recruited from the movement disorders clinic at our hospital. Their mean (range) age was 71 (54-80) years, and the mean (range) duration of disease was 11 (7-15) years. All were receiving levodopa/ decarboxylase inhibitor with a mean (range) duration of treatment of 9.8 (5-15) years and five were also using intermittent subcutaneous apomorphine at a mean (range) dose of 3.2 (1.5-6) mg. All had symptomatic motor fluctuations in response to levodopa (mean (range) duration of fluctuations 2.2 (1-6) years).

Patients were studied under identical standardised conditions on two mornings one week apart. All antiparkinsonian medication was withheld for a minimum of eight hours and patients were fasted for four hours before the study. Serial motor assessments were carried out at 15 minute intervals and consisted of $(a)$ the time taken to rise from a standard armless chair, walk $6 \mathrm{~m}$, and return to sit in the chair and (b) a modified Webster disability scale (scoring for 12 areas of motor function giving a maximum disability score of 36$).{ }^{13}$ On the first study day in their clinical "off" motor state each patient underwent an initial modified barium swallow (see below). After completion they were given a single oral dose of $250 \mathrm{mg}$ levodopa/25 mg carbidopa. When a stable improvement in motor state had occurred, approximating each patients previously observed "on" motor state the modified barium swallow was repeated. On the second study day the sequence was repeated using a dose of apomorphine adequate to reliably reverse that patients "off" motor state, mean (range) dose 
3.5 (1.5-6) mg. For those patients not using regular apomorphine the dose was chosen according to an apomorphine test using escalating doses carried out on a previous occasion. When studied with apomorphine patients were pretreated with 72 hours of the peripheral dopamine receptor blocking drug domperidone.

The procedure was thoroughly explained to each patient before testing and each was monitored carefully throughout the study to avoid factors that may influence performance such as anxiety and fatigue. The modified barium swallows were performed according to a standard protocol. ${ }^{14}$ Subjects were seated in a lateral position within $30 \mathrm{~cm}$ of the screen. Screening was performed at $70 \mathrm{kV}$ using a specialised fluoroscopic unit (Shimadzu Image Intensifier). Video and sound recordings were made on a Panasonic Super VHS recorder, with frame by frame control (25 frames/s). Three food consistencies of standardised bolus size were used-namely, thin liquid ( $5 \mathrm{ml}$, equivalent to milk), semisolid (about $3 \mathrm{ml}$, equivalent to jelly), and solid (about $5.8 \mathrm{~cm}^{3}$, dry toast coated in barium). The videos were evaluated independently by two speech pathologists experienced in analysis of modified barium swallows who had not been present at the time of the study and who were blinded to the patient and timing of the swallow in relation to the dopaminergic challenge. Previous studies from our department and elsewhere have shown a high degree of within and between observer reliability for examination of oral and pharyngeal function using videofluoroscopy. ${ }^{14-16}$ As this was also the case in the present study, data from only one of the raters were chosen for analysis. In view of both the somewhat artificial nature of the testing environment and the inconsistency between parkinsonian patients' self reporting of swallowing dysfunction and videofluoroscopic findings it was elected not to assess each patient's subjective impression of any change in their swallowing after levodopa and apomorphine. ${ }^{17}$

Qualitative measures of swallowing function were recorded on a four point scale of severity according to the estimated percentage of the original bolus volume (nil, mild $<10 \%$, moderate $10 \%-39 \%$, or severe $40 \%-100 \%){ }^{14}$ These were defined as: aspiration-permanent entry of food or fluid into the laryngeal vestibule; laryngeal penetration - entry of food or fluid into the laryngeal vestibule which cleared safely within five seconds of entry; vallecular pooling-bolus remaining in one or both valleculae after the initial swallow. The place of the bolus when swallowing was initiated was recorded (when laryngeal elevation commenced) as either anterior to the velum, between the velum and valleculae, or subepiglottic.

Timed components of swallowing, similar to those used in previous studies,${ }^{17}{ }^{18}$ included the following quantitative measures: oral preparatory phase-time from entry of bolus through the lips to the commencement of the oral phase; oral phase - time from initial movement of the head of the bolus in the mouth to the head of the bolus reaching the posterior aspect of the ramus of the mandible; pharyngeal phase-commencing when the head of the bolus passed the ramus of the mandible until it passed through the cricopharyngeus (upper oesophageal sphincter); rapid pharyngeal transit-(a subcomponent of the pharyngeal phase) beginning from the point of maximal excursion of the hyoid (initiation of swallow) until the bolus passed through cricopharyngeus; total initial swallow - the sum of the oral preparatory, oral and pharyngeal phases, and complete swallow-time from the entry of the bolus in the mouth until further swallows were not initiated or the patient reported that the bolus had been completely cleared (in some patients this was a subjective end point with the patient incorrectly thinking that the bolus had been cleared). Also recorded were the number of posterior tongue elevations-defined as the number of complete contacts of the posterior tongue and velum until initiation of the first swallow and the number of swallows to clear the pharynx of the bolus-defined as the number of laryngeal elevations which occurred until the total bolus passed through the cricopharyngeus (or to when the subject reported the bolus to have cleared). Oesophageal function was not evaluated.

The data were analysed using SPSS software with the comparison of premedication and postmedication swallowing variables analysed by non-parametric Wilcoxon signed rank test given the small sample size and the nonnormality of the distribution of the data. The motor response variables were compared by paired $t$ test. To correct for a possible dilutional effect of the more normal swallows to mask changes that may have occurred in the more abnormal swallows we also analysed the response of the seven most abnormal results for each of the timed criteria using the Wilcoxon signed rank test.

\section{Results}

MOTOR RESPONSE

As would be expected in patients with symptomatic motor fluctuations there was a significant improvement in the Webster score and walking time after both levodopa and apomorphine challenges (both $\mathrm{P}<0.01$ ). The mean (range) change in Webster score was 8.5 (6-13) after levodopa and 7.9 (4-14) after apomorphine, whereas the mean (range) improvement in walking time was $31.8(0-70) \mathrm{s}$ after levodopa and 24.8 (3-70) $\mathrm{s}$ after apomorphine. There was no significant difference between the improvement seen with levodopa and apomorphine.

SWALLOWING FUNCTION

Of the 60 modified barium swallows performed, incorporating 180 swallows there were seven instances of aspiration, 21 instances of laryngeal penetration, 158 instances of vallecular pooling, and 47 instances of subepiglottic initiation of the swallow. There were no significant differences in any of the variables between the two baseline (pretreatment) modified barium swallows separated by one week. 
Table 1 Comparison of non-timed variables before (off) and after (on) administration of oral levodopa and subcutaneous apomorphine for three bolus consistencies

\begin{tabular}{|c|c|c|c|c|c|c|c|c|c|c|c|c|}
\hline & \multicolumn{4}{|c|}{ Semisolids } & \multicolumn{4}{|c|}{ Thin fluids } & \multicolumn{4}{|c|}{ Solids } \\
\hline & \multicolumn{2}{|c|}{ Levodopa } & \multicolumn{2}{|c|}{ Apomorphine } & \multicolumn{2}{|c|}{ Levodopa } & \multicolumn{2}{|c|}{ Apomorphine } & \multicolumn{2}{|c|}{ Levodopa } & \multicolumn{2}{|c|}{ Apomorphine } \\
\hline & Off & $O n$ & Off & $O n$ & Off & $O n$ & Off & $O n$ & Off & $O n$ & Off & $O n$ \\
\hline \multicolumn{13}{|l|}{ Aspiration: } \\
\hline None & 15 & 14 & 15 & 13 & 15 & 14 & 15 & 15 & 15 & 14 & 14 & 13 \\
\hline Mild & 0 & 1 & 0 & 1 & 0 & 1 & 0 & 0 & 0 & 1 & 1 & 1 \\
\hline Moderate to severe & 0 & 0 & 0 & 0 & 0 & 0 & 0 & 0 & 0 & 0 & 0 & 1 \\
\hline \multicolumn{13}{|l|}{ Laryngeal penetration: } \\
\hline None & 15 & 14 & 12 & 13 & 13 & 13 & 15 & 15 & 12 & 12 & 12 & 13 \\
\hline Mild & 0 & 1 & 2 & 1 & 2 & 1 & 0 & 0 & 3 & 3 & 3 & 2 \\
\hline Moderate to severe & 0 & 0 & 1 & 1 & 0 & 1 & 0 & 0 & 0 & 0 & 0 & 0 \\
\hline \multicolumn{13}{|l|}{ Vallecular pooling: } \\
\hline None & 4 & 6 & 4 & 3 & 0 & 0 & 0 & 0 & 0 & 1 & 1 & $1^{\star}$ \\
\hline Mild & 9 & 7 & 10 & 8 & 10 & 11 & 11 & 10 & 11 & 7 & 5 & 10 \\
\hline Moderate to severe & 2 & 1 & 1 & 3 & 5 & 4 & 4 & 5 & 4 & 7 & 9 & 4 \\
\hline $\begin{array}{l}\text { Swallows to clear pharynx } \\
\text { (mean) }\end{array}$ & 2.7 & 2.5 & 3.1 & 3.2 & 3.8 & 2.8 & 3.1 & 2.9 & 3.8 & $3.1^{\star}$ & 3.4 & 2.5 \\
\hline $\begin{array}{l}\text { Number of tongue elevations } \\
\text { (mean) }\end{array}$ & 1.8 & 1.6 & 1.6 & 1.6 & 1.2 & 1.2 & 1.5 & 2 & 8 & 4.8 & 5.1 & 5.1 \\
\hline \multicolumn{13}{|l|}{ Place of bolus: } \\
\hline Anterior to velum & 5 & 3 & 3 & 3 & 7 & $7^{\star}$ & 6 & $2^{\star}$ & 3 & 2 & 3 & $3^{\star}$ \\
\hline Velum to valleculae & 4 & 8 & 7 & 4 & 5 & 6 & 5 & 8 & 10 & 11 & 10 & 7 \\
\hline Subepiglottic & 6 & 4 & 5 & 8 & 2 & 2 & 4 & 5 & 2 & 2 & 2 & 5 \\
\hline
\end{tabular}

$\star \mathrm{P}<0.05$.

Results expressed as the number of patients in each category except where mean is specified. See text for definitions of criteria.

For qualitative variables (table 1), few significant differences were found after levodopa or apomorphine. The only differences seen in the group as a whole were less vallecular pooling with the solid bolus after administration of apomorphine $(\mathrm{P}<0.05)$, not seen after levodopa, and fewer swallows to clear the solid bolus only after levodopa administration $(\mathrm{P}<0.05)$.

The quantitative assessment, when all patients were analysed (table 2), disclosed that there was a reduction in the oral preparatory phase with both semisolids and thin fluids after levodopa $(\mathrm{P}<0.05)$. This was not seen with solids and failed to reach significance after apomorphine $(0.05<P<0.1)$. Somewhat unexpectedly there was an increase in the oral phase time and the total initial swallow time with the solid bolus alone after administration of levodopa $(\mathrm{P}<0.05)$. The only other significant result was a reduction in the rapid pharyngeal transit time with semisolids after apomorphine $(\mathrm{P}<0.01)$.

Analysis of the seven most abnormal results for each timed criteria showed that abnormalities were distributed across all 15 patients. This analysis supported the findings in the group as a whole, with a significant reduction occurring in the oral preparatory phase with both semisolids (from mean (SE) of $0.63(0.16) \mathrm{s}$ to $0.16(0.04) \mathrm{s}$ ) and thin fluids (from $2.0(0.64)$ $\mathrm{s}$ to $0.91(0.58) \mathrm{s})$ after levodopa. In addition, the reduction in the oral preparatory phase with semisolids after apomorphine also now reached significance (from $0.63(0.13) \mathrm{s}$ to $0.34(0.1) \mathrm{s})$. The reduction in rapid pharyngeal transit time with semisolids after apomorphine was again significantly reduced (from $0.44(0.1) \mathrm{s}$ to $0.33(0.1) \mathrm{s})$ with the reduction in pharyngeal phase time also reaching significance (from $3.87(0.62) \mathrm{s}$ to $2.72(1.0) \mathrm{s}$ ). In this analysis the reduction in pharyngeal phase

Table 2 Comparison of timed variables before (off) and after (on) administration of oral levodopa and subcutaneous apomorphine for three bolus consistencies

\begin{tabular}{|c|c|c|c|c|c|c|c|c|c|c|c|c|}
\hline & \multicolumn{4}{|c|}{ Semisolids } & \multicolumn{4}{|c|}{ Thin fluids } & \multicolumn{4}{|l|}{ Solids } \\
\hline & \multicolumn{2}{|c|}{ Levodopa } & \multicolumn{2}{|c|}{ Apomorphine } & \multicolumn{2}{|c|}{ Levodopa } & \multicolumn{2}{|c|}{ Apomorphine } & \multicolumn{2}{|c|}{ Levodopa } & \multicolumn{2}{|c|}{ Apomorphine } \\
\hline & Off & On & Off & On & Off & On & Off & On & Off & On & Off & On \\
\hline $\begin{array}{l}\text { Oral preparatory } \\
\text { phase }\end{array}$ & $\begin{array}{l}0.40 \\
(0.09)\end{array}$ & $\begin{array}{l}0.20^{\star} \\
(0.04)\end{array}$ & $\begin{array}{l}0.42 \\
(0.67)\end{array}$ & $\begin{array}{l}0.31 \\
(0.08)\end{array}$ & $\begin{array}{l}1.30 \\
(0.44)\end{array}$ & $\begin{array}{l}0.65^{\star} \\
(0.35)\end{array}$ & $\begin{array}{l}2.3 \\
(0.8)\end{array}$ & $\begin{array}{l}1.75 \\
(0.57)\end{array}$ & $\begin{array}{l}0.34 \\
(0.08)\end{array}$ & $\begin{array}{l}0.30 \\
(0.07)\end{array}$ & $\begin{array}{l}0.29 \\
(0.05)\end{array}$ & $\begin{array}{l}0.49 \\
(0.19)\end{array}$ \\
\hline Oral phase & $\begin{array}{l}4.44 \\
(1.21)\end{array}$ & $\begin{array}{l}4.20 \\
(1.01)\end{array}$ & $\begin{array}{l}5.2 \\
(0.87)\end{array}$ & $\begin{array}{l}5.90 \\
(1.13)\end{array}$ & $\begin{array}{l}1.77 \\
(0.39)\end{array}$ & $\begin{array}{l}2.28 \\
(0.93)\end{array}$ & $\begin{array}{l}3.75 \\
(1.38)\end{array}$ & $\begin{array}{l}3.61 \\
(0.82)\end{array}$ & $\begin{array}{l}18.24 \\
(2.69)\end{array}$ & $\begin{array}{l}24.01^{\star} \\
(2.18)\end{array}$ & $\begin{array}{l}42.37 \\
(21.4)\end{array}$ & $\begin{array}{l}22.0 \\
(1.95)\end{array}$ \\
\hline $\begin{array}{l}\text { Pharyngeal phase } \\
\text { time }\end{array}$ & $\begin{array}{l}1.70 \\
(0.47)\end{array}$ & $\begin{array}{l}1.64 \\
(0.44)\end{array}$ & $\begin{array}{l}2.23 \\
(0.51)\end{array}$ & $\begin{array}{l}2.72 \\
(0.73)\end{array}$ & $\begin{array}{l}1.41 \\
(0.52)\end{array}$ & $\begin{array}{l}0.63 \\
(0.22)\end{array}$ & $\begin{array}{l}1.28 \\
(0.56)\end{array}$ & $\begin{array}{l}1.08 \\
(0.37)\end{array}$ & $\begin{array}{l}4.7 \\
(1.95)\end{array}$ & $\begin{array}{l}2.7 \\
(1.02)\end{array}$ & $\begin{array}{l}3.65 \\
(0.95)\end{array}$ & $\begin{array}{l}3.30 \\
(1.24)\end{array}$ \\
\hline $\begin{array}{l}\text { Rapid pharyngeal } \\
\text { transit }\end{array}$ & $\begin{array}{l}0.28 \\
(0.03)\end{array}$ & $\begin{array}{l}0.29 \\
(0.05)\end{array}$ & $\begin{array}{l}0.31 \\
(0.05)\end{array}$ & $\begin{array}{l}0.26^{\star} \\
(0.05)\end{array}$ & $\begin{array}{l}0.36 \\
(0.07)\end{array}$ & $\begin{array}{l}0.27 \\
(0.03)\end{array}$ & $\begin{array}{l}0.28 \\
(0.3)\end{array}$ & $\begin{array}{l}0.27 \\
(0.03)\end{array}$ & $\begin{array}{l}0.39 \\
(0.06)\end{array}$ & $\begin{array}{l}0.43 \\
(0.1)\end{array}$ & $\begin{array}{l}0.38 \\
(0.05)\end{array}$ & $\begin{array}{l}0.31 \\
(0.05)\end{array}$ \\
\hline $\begin{array}{l}\text { Total initial } \\
\text { swallow }\end{array}$ & $\begin{array}{l}6.79 \\
(1.32)\end{array}$ & $\begin{array}{l}5.78 \\
(1.03)\end{array}$ & $\begin{array}{l}7.69 \\
(0.93)\end{array}$ & $\begin{array}{l}7.99 \\
(1.12)\end{array}$ & $\begin{array}{l}4.01 \\
(0.84)\end{array}$ & $\begin{array}{l}3.27 \\
(0.88)\end{array}$ & $\begin{array}{l}7.18 \\
(1.94)\end{array}$ & $\begin{array}{l}6.42 \\
(1.1)\end{array}$ & $\begin{array}{l}19.99 \\
(2.92)\end{array}$ & $\begin{array}{l}27.4^{\star} \\
(2.55)\end{array}$ & $\begin{array}{l}26.34 \\
(3.17)\end{array}$ & $\begin{array}{l}26.72 \\
(2.88)\end{array}$ \\
\hline Complete swallow & $\begin{array}{l}19.4 \\
(2.24)\end{array}$ & $\begin{array}{l}15.72 \\
(1.69)\end{array}$ & $\begin{array}{l}20.28 \\
(3.32)\end{array}$ & $\begin{array}{l}20.6 \\
(9.37)\end{array}$ & $\begin{array}{l}25.2 \\
(3.99)\end{array}$ & $\begin{array}{l}16.1^{\star} \\
(3.8)\end{array}$ & $\begin{array}{l}24.02 \\
(4.54)\end{array}$ & $\begin{array}{l}26.66 \\
(4.9)\end{array}$ & $\begin{array}{l}49.57 \\
(8.04)\end{array}$ & $\begin{array}{l}47.32 \\
(6.15)\end{array}$ & $\begin{array}{l}49.45 \\
(6.19)\end{array}$ & $\begin{array}{l}49.34 \\
(5.8)\end{array}$ \\
\hline
\end{tabular}

All results are means (SE) in seconds.

${ }^{\star} \mathrm{p}<0.05$. 
time and rapid pharyngeal transit with thin fluids after levodopa also reached significance (from $2.71(0.9) \mathrm{s}$ to $0.86(0.47) \mathrm{s}$ and from $0.52(0.1)$ s to 0.32 (0.05) s respectively).

\section{Discussion}

The type and severity of swallowing abnormalities found were similar to those described previously in parkinsonian dysphagia..$^{2-5}$ Previous studies have differed in the response of parkinsonian dysphagia to dopaminergic medication. ${ }^{418-20}$ Some found no improvement ${ }^{8}$ whereas others suggested a response in some patients. ${ }^{8}{ }^{18-20}$ In some studies improvement was evaluated descriptively, without attempting statistical analysis, ${ }^{40}$ whereas others did not control carefully for the timing of medication. ${ }^{8} 19$

The patients studied had large amplitude motor fluctuations and symptomatic dysphagia and were thus thought most likely to show any possible response to dopaminergic medication. However, little consistent improvement occurred. The few results that reached significance may have occurred by chance given the number of variables and conditions studied. An improvement in the oral preparatory phase time was seen with levodopa in the group as a whole, and after apomorphine in the subgroup of patients with the most abnormal results, but only with some bolus consistencies. It has been suggested that rigidity and bradykinesia of oral musculature may underlie abnormalities in the oral preparatory phase, which is under volitional control, and it would therefore seem logical for there to be an improvement in this phase. ${ }^{10}$ This is consistent with a report that improvement in buccolinguofacial motor function correlated with a reduction in the duration of total swallow after administration of apomorphine. ${ }^{18}$ However, we found that other variables, which involve similar muscle action and volitional control, including the number of tongue elevations and the length of the oral phase, failed to improve.

There were some significant changes among the more automatic, non-voluntary components of the swallow. In the group as a whole a reduction in the rapid pharyngeal transit time was seen with semisolids after apomorphine. A reduction in the pharyngeal phase time occurred with some food consistencies in the group with the most prolonged times after both levodopa and apomorphine. This finding concurs with a recent study using similar methodology which reported a reduction in pharyngeal phase time with thin fluids after apomorphine. ${ }^{18}$ Unexpectedly an increase in the oral phase time and the total initial swallow time was also seen, solely with the solid bolus after levodopa. Although this finding is difficult to explain and goes against the other results, an isolated case of deterioration of swallowing after levodopa has been described in an earlier series. ${ }^{4}$

It is possible that the limited number of patients studied may have led to a type 2 error, or that the more normal swallows may have masked a significant response in the more abnormal swallows. In our patient population fewer abnormalities were seen in some of the variables studied than in some earlier series, making it unlikely that a significant improvement could be shown. ${ }^{3-5} 18$ However, none of the results for individual patients showed a large amplitude response to more than a few of the swallowing criteria, whereas all showed an unequivocal motor response. Although it is also possible that the variables chosen were not sensitive enough to detect any improvement, similar methodology has been previously employed in studies of this type and in other clinical settings. ${ }^{4101518}$ It needs to be pointed out that this study only assessed the short duration response to dopaminergic medication. Other factors such as inexperience, anxiety, fatigue, and learning that could have influenced patients' performance during the modified barium swallows seemed to have negligible effects.

Swallowing is regulated by a hierarchical system extending from the frontal and limbic cortices to the basal ganglia, hypothalamus, pons, and medulla. The neural programmes which control and coordinate the serial muscular activity are stored in medullary nuclei which have the properties of central pattern generators. ${ }^{21}$ These are best thought of as hard wired neural networks with a menu of stock programmes which are enacted serially to produce a smoothly coordinated series of muscle contractions. The medullary central pattern generators are thought to be located in the medial reticular formation of the rostral medulla (pharyngeal phase) and in the reticulum adjacent to the nucleus tractus solitarius (pharyngeal and oesophageal phases). ${ }^{21}$ They project to the nucleus ambiguus, which innervates the striated muscles of the oesophagus, pharynx, and larynx, ${ }^{22}$ and the dorsal motor nucleus of the vagus, which controls muscular contraction in the remaining oesophagus. ${ }^{21}$

Dorsal motor nucleus parasympathetic and nucleus ambiguus primary motor neurons are cholinergic whereas the nucleus tractus solitarius receives a cholinergic input from the pedunculopontine tegmental nucleus. ${ }^{22}$ The role of other neurotransmitters that are also found in these medullary nuclei, such as noradrenaline, glutamate, nitrous oxide, Substance P, enkephalin, somatostatin, and GABA is not clear.

In Parkinson's disease there is selective neuronal degeneration in the dorsal motor nucleus and the pedunculopontine tegmental nucleus, with the nucleus ambiguus and nucleus tractus solitarius apparently spared..$^{23}$ Substance P neurons in the dorsal motor nucleus are preferentially affected, whereas catecholaminergic neurons appear intact. ${ }^{25}$ Studies of changes of other neurochemical systems have not been performed. The potential peripheral role of dopamine acting in the oesophageal myenteric plexus where local neuronal degeneration with Lewy bodies has been shown is uncertain and likely to relate solely to oesophageal dysfunction. ${ }^{26}$

It would seem likely that in Parkinson's disease, swallowing dysfunction is mediated by dysfunction of non-dopaminergic mechanisms 
in the medullary central pattern generators in addition to the increased inhibitory outflow from the pallidum to the pedunculopontine tegmental nucleus due to the loss of dopaminergic input into the striatum. The pattern of parkinsonian swallowing dysfunction conforms with the general thesis that the motor deficits of Parkinson's disease are due to the abnormal enactment of sequential muscle contraction during automatic motor acts. The abnormalities can be seen in terms of a disruption to the normal sequencing of swallowing and thus would fit with the disruption seen in other motor sequencing in Parkinson's disease.

The results of this study are further evidence that, unlike the cardinal motor features of Parkinson's disease, swallowing dysfunction is predominantly resistant to dopaminergic stimulation. They clinically support evidence that other neurotransmitter systems involved in the neurological control and coordination of swallowing are damaged in Parkinson's disease. Further studies are needed to delineate the systems involved with a view to therapeutic intervention.

This study was supported in part by funding from Aged Care Services research fund. We gratefully acknowledge the cooperation of the Radiology department of the Austin and Repatriation Medical Centre and Dr Elena Kulinskaya for invaluable statistical advice.

1 Eadie MJ, Tyrer JH. Alimentary disorders in parkinsonism. Aust Ann Med 1965;14:13-22.

2 Edwards LL, Quigley EMM, Pfeiffer RF. Gastrointestinal dysfunction in Parkinson's disease: frequency and pathophysiology. Neurology 1992;42:726-32.

3 Stroudley J, Walsh M. Radiological assessment of dysphagia in Parkinson's disease. Br F Radiol 1991;64:890-3.

4 Bushmann M, Dobmeyer SM, Leeker L, Perlmutter JS. Swallowing abnormalities and their response to treatment in Parkinson's disease. Neurology 1989;39:1309-14.

5 Logemann JA, Blonsky ER, Boshes B. Dysphagia in Parkinsonism. FAMA 1975;231:69-70.

6 Silbiger MC, Pikielney R, Donner MW. Neuromuscular disorders affecting the pharynx: cineradiographic analysis. orders affecting the pharyn:
Invest Radiol 1967;2:442-8.

7 Kahrilas PJ, Logemann JA, Krugler C, Flanagan E. Volitional augmentation of upper esophageal sphincter opening during swallowing. Am f Physiol 1991;260:G450-56.
8 Calne DB, Shaw DG, Spiers ASD, Stern GM. Swallowing in parkinsonism. Br f Radiol 1970;43:456-57.

9 Galib NA, Wallace KL, Schwartz R, Decarle DJ, Zagami AS, Cook IJ. Mechanisms of oral-pharyngeal dysphagia in patients with Parkinson's disease. Gastroenterology 1996; 110:382-92.

10 Robbins J, Logemann JA, Kirshner HS. Swallowing and speech production in Parkinson's disease. Ann Neurol 1986;19:283-7.

11 Gibberd FB, Gleeson JA, Glossage AAR, Wilson RSE. Oesophageal dilatation in Parkinson's disease. $f$ Neurol Neurosurg Psychiatry 1974;37:938-40.

12 Gibb WRG, Lees AJ. The Relevance or the Lewy body to the pathogenesis of idiopathic Parkinson's disease. 7 Neurol Neurosurg Psychiatry 1988;51:745-52.

13 Kempster PA, Frankel JP, Bovington M J, et al. Levodopa peripheral pharmacokinetics and duration of motor responses in Parkinson's disease. F Neurol Neurosurg Psychiatry 1989;52:718-23.

14 Gibson E, Phyland D, Marschner I. Rater reliability of the modified barium swallow. Australian fournal of Human Communication Disorders 1995;23:54-60.

15 Ekberg D, Nylander G, Fork F, Sjoberg S, Birch-lensen M, Hillarp B. Interobserver variability in cineradiographic assessment of pharyngeal function during swallowing. Dysphagia 1988;3:46-8.

16 Robbins J, Hamilton JW, Gregory L, Kempster GB. Oropharnygeal swallowing in normal adults of different ages. Gastroenterology 1992;103:823-29.

17 Bird MR, Woodward MC, Gibson EM, Phyland DJ, Fonda D. Asymptomatic swallowing disorders in elderly patients with Parkinson's disease: a description of findings on clinical examination and videofluoroscopy in sixteen patients. Age Ageing 1994;23:251-4.

18 Tison F, Wiart L, Guatterie N, et al. Effects of central dopaminergic stimulation by apomorphine on swallowing disorders in Parkinson's disease. Mov Disord 1996;11:72932 .

19 Paulson GR, Tafrate RH. Some minor aspects of parkinsonism especially pulmonary function. Neurology 1970;20:147.

20 Fonda D, Schwarz J. Parkinsonian medication one hour before meals improves symptomatic swallowing: a case study. Dysphagia 1995;10:165-6

21 Miller AJ. Neurophysiological basis of swallowing. Dysphagia 1986;1:91-100.

22 Carpenter MB. Core text of neuroanatomy, 3rd ed. Baltimore: Williams and Wilkins, 1985:102-32.

23 Rye DB, Lee HJ, Sapper CB, Wailer BH. Medullary and spinal efferents of the pedunculopontine tegmental nucleus. F Comp Neurol 1988;269:315-41.

24 Jellinger K. Overview of morphological changes in Parkinson's disease. Adv Neurol 1986;45:1-18.

25 Halliday GM, Li YW, Blumbergs PC, et al. Neuropathology of immunohistochemically identified brainstem neurons in Parkinson's disease. Ann Neurol 1990;27:373-85.

26 Qualman SJ, Haupt HM, Yang P, et al. Esophageal Lewy bodies associated with ganglion cell loss in achalasia: similarity to Parkinson's disease. Gastroenterology 1984;87:848-56. 